\title{
Flipped Classroom in Higher Education: A Bibliometric Analysis and Proposal of a Framework for its Implementation
}

\author{
https://doi.org/10.3991/ijet.v16i09.21267 \\ Cesar H. Limaymanta $(\bowtie)$ \\ Universidad Nacional Mayor de San Marcos, Lima, Peru \\ climaymantaa@unmsm. edu.pe \\ Universidad Peruana de Ciencias Aplicadas, Lima, Peru \\ pcmaclimeupc.edu.pe \\ Ludgarda Apaza-Tapia, Elizabeth Vidal \\ Universidad Nacional de San Agustín de Arequipa, Arequipa, Peru \\ Orlando Gregorio-Chaviano \\ Pontificia Universidad Javeriana, Bogotá, Colombia
}

\begin{abstract}
The flipped classroom as an educational model is perfectly aligned with the current demands of higher education. Therefore, the objectives of this article were to carry out a bibliometric analysis of the scientific production of the flipped classroom in higher education (2012-2020) and to propose a framework for its implementation in face-to-face, blended or online learning modalities. The records were recovered from the Web of Science Core Collection and Scopus, from which, after a five-phase methodological process, a consolidated dataset of 782 documents was obtained. The results showed the importance of the subject matter as scientific production reflected a continuous growth during the period of study. For their part, the most productive authors come from various institutions worldwide with an $\mathrm{H}$ index of over 50. The collaboration indicators show the growth trend of these indexes over the years, which reflects the capacity to generate national and international impact in the documents published in collaboration. The keywords co-occurrence analysis showed that the flipped classroom as a technological and innovative approach is complemented by active learning, blended learning, e-learning, ICT, teaching method, among others. Finally, a framework with five components was proposed as a basic guide for the implementation of the flipped classroom in higher education.
\end{abstract}

Keywords - Flipped classroom; Bibliometrics; Higher education; Active learning; Framework; Scientific collaboration; Co-occurrence; Scientific production; Information and communication technology 


\section{Introduction}

Active learning has its axis in pedagogy centered on the activity of the student and his or her involvement in the process of teaching and learning [1]. There are several methods that enable active learning such as concept mapping, brainstorming, collaborative writing, case-based instruction, cooperative learning, role-playing, simulation, project-based learning and peer teaching [2]. Active learning pedagogies have continued to evolve, and new methods have been developed with innovative ways of restructuring learning sessions, such as flipped classroom and gamification ([3]-[5].

In 2007, in Colorado, USA, Jonathan Bergmann and Aaron Sams, chemistry teachers, systematically shaped the use of the flipped classroom (FC) and are considered the founders of this pedagogical model. Since then the FC has spread to a wide community of educational institutions and educators around the world, reaching out to higher education [6]. The FC as a pedagogical model requires the commitment and active participation of students in learning activities both before and in the classroom, all with the contribution of information and communication technologies [7]-[9].

The FC offers students the opportunity to self-regulate their learning, for example, to explore materials such as videos, readings or exercises at their own pace [7]. Preclass activities allow students to use their learning time independently to acquire fundamental knowledge and skills. While during classes (face-to-face or synchronous), students participate individually and collaboratively, receiving individualized support from the professor [10]-[12]. Classroom activities are student-centred, emphasizing active learning, where the teacher helps the student and not just provides information; this makes them self-directed learners [4], [13], [14]. Therefore, some of the benefits of the application of the FC are improved attention, verification of learning, allows for self-assessment and empowerment of the student in the assessment processes that adapts to their individual interests with flexibility to make decisions about the what, the how and the when, and they learn by assuming commitment and responsibility [15], [16].

The development of information and communication technologies (ICT) and the current situation made the implementation of virtual education the standard at all levels of education. For this reason, higher education institutions have implemented institutional strategies, where professors have carried out trials that serve to achieve learning, a trend that shows that the characteristics of teaching will not be the same in the future [17]. In this context, the covid-19 has accelerated the demand for digital transformation in higher education institutions and professors have been challenged to achieve adaptability and flexibility in the content and design of courses for learning in different training areas. With this, the disruption of traditional teaching becomes evident with online learning models, where the FC has found the most favourable ground to be used and developed with new particularities and demands [12], [16], [18], [19].

There are various methodologies applied in the FC, so their application depends on the mentality, ability, culture, or preference of professors and students. There is no ideal route that guarantees good results [13]. However, once the pedagogical proposal is defined, teaching-learning strategies will be designed with the use of ICT and didactics to achieve the competences foreseen in the pedagogical design. Authors such 
as Kim et al. [20], Lo \& Hwang [21], DePietro et al. [12] and Hew et al. [18] used the framework as a tool that provides a cohesive structure with validated components. It is adaptable because it allows for different learning styles and areas to be worked with according to the needs of professors and students.

Knowing the trends and regularities of scientific disciplines is therefore necessary and important, and where bibliometrics as an instrumental discipline with a long tradition in the evaluation of science allows the analysis of the behaviour of scientific production in different scientific aggregates by means of bibliometric methods and indicators, with a mathematical-statistical basis [22], [23]. The use of these bibliometric methods and indicators to study the behaviour of disciplines and areas of knowledge is of vital importance given their contributions to the knowledge of the regularities and trends present in the scientific production generated by scientific communities [24]. Obtaining indicators that enable analysis from different perspectives and dimensions (productivity, visibility and impact, networks), as well as helping to understand the aforementioned behaviours and trends, provides key information for the management of scientific activity by specialised communities and the generation of new knowledge [25]. Technological development and computerized methods have facilitated the obtaining of indicators and the visualization of information that help to improve the analysis of results and the regularities present in the results [26]. These provide a powerful approach to analysing a wide variety of bibliometric networks, ranging from networks of dating relationships to networks of co-authorship or co-occurrence relationships [27], [28].

There are previous bibliometric studies related to FC in general [29]-[32]. Their works were oriented to analyzing the growth of scientific production on FC, productivity according to countries, thematic categories, journals, frequency of keywords, impact through citations and bibliometric networks of the analyzed documents. In the field of higher education only studies of reviews, systematic review and meta-analysis of FC were found, some of them are [33]-[35]. These authors highlighted the importance of the use of FC in higher education, demonstrated the improvement in academic performance and student satisfaction with the FC model, and described the main findings or conclusions of the papers analysed in the context of higher education.

In this scenario, the contribution of this article is based on the achievement of two objectives: (1) To identify the behavior of the FC's scientific production in higher education based on indicators of production, collaboration and bibliometric networks, and (2) To propose a framework for implementing the FC in higher education in the modalities of face-to-face, blended or online learning. The first objective is based on bibliometrics as a suitable tool for analysis. For the second objective, some results of the bibliometric analysis have been used in conjunction with the review of the literature [36] to propose a framework for the proper implementation and use of the FC with five basic components: (a) planning, (b) induction session, (c) pre-class activities, (d) in-class activities, and (e) post-class activities. 


\section{Methodology}

\subsection{Design and information source}

The work is a descriptive study with bibliometric methodology that examines the behaviour of scientific production on FC in higher education. For the search and retrieval of the information, the most recognized multidisciplinary database platforms worldwide were used, Web of Science (WoS) Core Collection and Scopus in the period 2012 to October 2020. For the retrieval of records and the creation of the working dataset, the search equation ("flipped classroom*" OR "inverted classroom*") AND (universit* OR college* OR varsit* OR "higher education" OR "undergraduate education") was used in the fields title, abstract or keywords. Only article or review depending on the quality of these documentary typologies and their contribution to visibility and impact. 2012 was taken as the starting year, because the records retrieved from both databases were recorded from that year onwards.

The 713 and 848 registers recovered from Web of Science and Scopus respectively (Fig. 1) were exported to EndNote, a bibliographic management system with bibliometric features, which made it possible to eliminate duplicates and subsequently create a single database with 1095 documents. Documents whose profiles did not meet the objectives of the study, such as studies that do not refer to higher education as a context or that do not refer to the FC as a learning methodology, were then excluded. After a clean-up process, 782 consolidated documents were obtained (Fig. 1.)

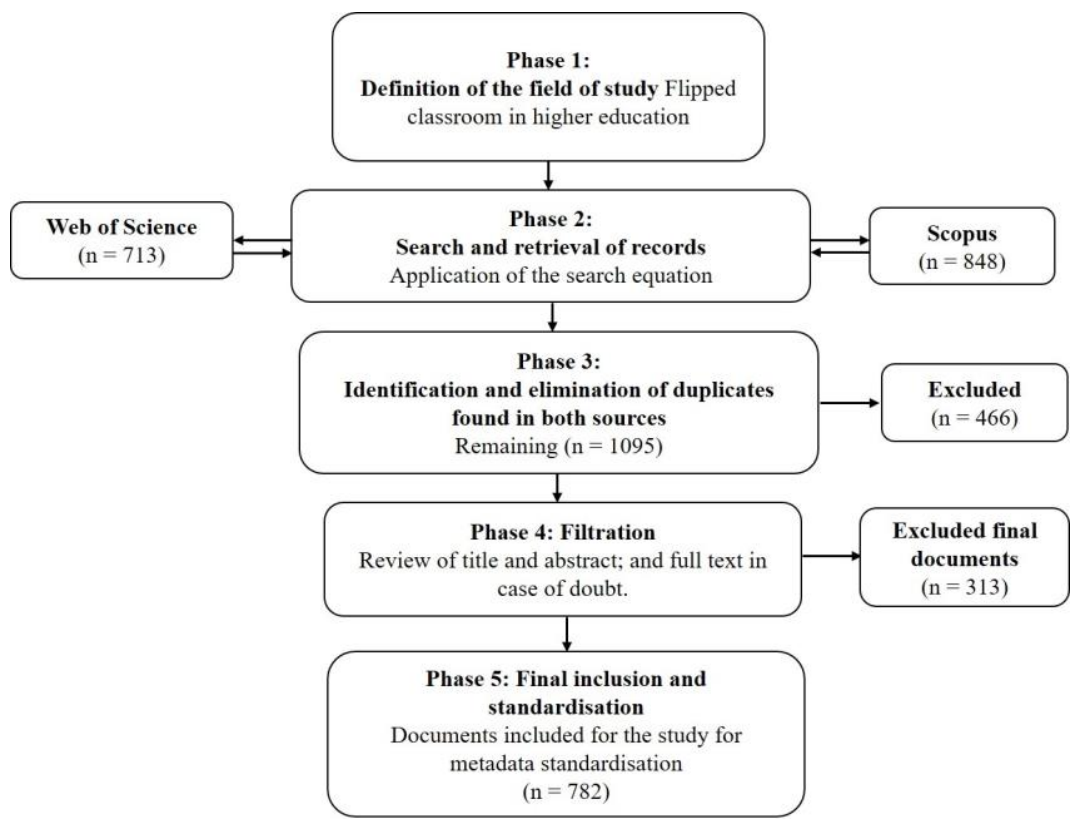

Fig. 1. Methodological process of search, retrieval, selection, standardisation and inclusion of documents for the study 


\subsection{Analysis and measurement units}

The units of analysis considered were articles, authors, documents and keywords. The units of measurement were the indicators of productivity, collaboration and the co-occurrence of keywords with bibliometric networks.

\subsection{Data analysis}

For the analysis of the information, the programs Excel 2019, Publish or Perish 7, EndNote X9 and VOSviewer v1.6.15 were used. After obtaining the 782 consolidated documents, the collaboration indicators were obtained with Publish or Perish and Excel. With Excel the data was prepared and a process of standardisation of author names and keywords was carried out by constructing thesauri in txt files. The VOSviewer program was used to map the distance-based bibliometric networks according to keywords co-occurrence. To obtain the visualization map, VOSviewer applies the association force normalization technique [37], then the VOS mapping technique "visualization of similarities" [38], and finally the clustering technique [39]. A cluster in the network is represented by a colour and is formed by a set of nodes or items closely related to each other, according to the co-occurrence of keywords, where each node is assigned exclusively to a cluster.

\section{Results}

Research on scientific production in a specific field is relevant to understand the behaviour of literature in order to suggest future lines of research to related and interested communities. The following results offer a descriptive view with bibliometric methodology. This chapter ends with the proposal of a framework for applying the FC in higher education.

\subsection{Scientific production (2012 - October 2020)}

In the two documentary typologies analysed: articles and reviews, the number of documents published reveals a sustained and continuous growth from 2012 to 2019 , the latter being the highest value (186 documents) (Fig. 2). Likewise, it can be seen that in 2020 there is a trend of growth in the number of publications (148 documents) as the date of data extraction was October 2020. This may be due to the effect of the covid-19 pandemic which generated an increase in the number of investigations. In terms of reviews, the highest number of publications also occurred in 2019 (10 documents) and, in general, they had a constant flow of publications even though the number is lower in relation to research articles. Review articles provide comprehensive information on the topic, answer some questions, and suggest new aspects or trends of FC research. 


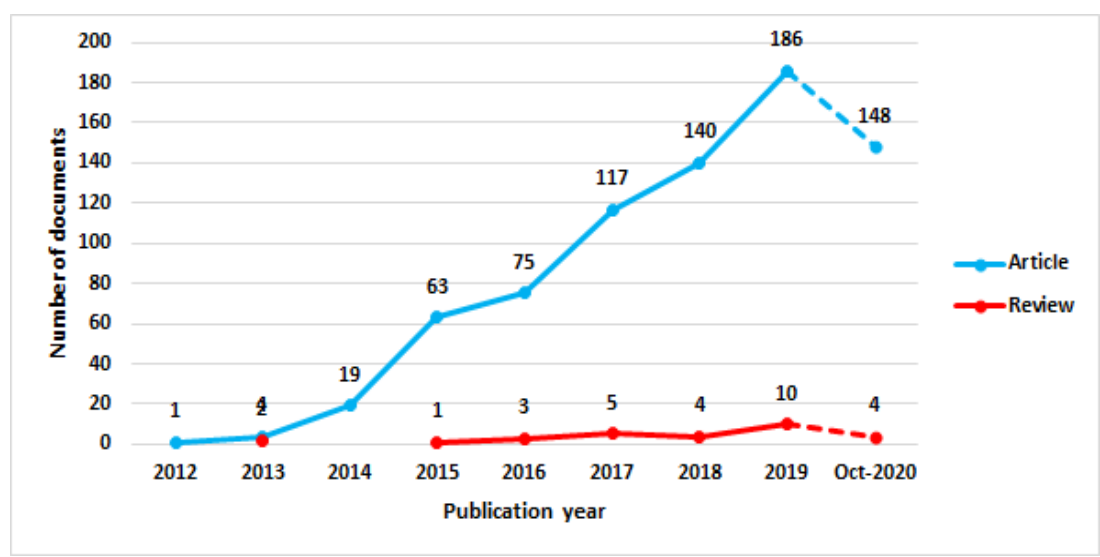

Fig. 2. Evolution of scientific production (2012- October 2020), articles and reviews

\subsection{Most productive authors}

The distribution of the top 20 authors who contributed most to the subject studied is shown, analysing the number of documents, their institution of affiliation and country, in addition to the $\mathrm{H}$ index (Table 1). The values of this last indicator were obtained from Scopus taking into account its coverage and therefore the possibility it offers of finding a greater number of authors and a wider knowledge of them. As information resulting from the analysis, it can be seen that the 20 authors are affiliated with institutions from various countries, mostly European, highlighting the participation of Spanish authors and the non-inclusion of authors from Latin America, even though Scopus was included as a source of databases with regional coverage.

The $\mathrm{H}$ index represents an indicator that shows, from two variables (production and citations) the performance of a researcher based on the distribution of citations in their articles published over a period of time. In the research, the $\mathrm{H}$ values of each author evidence the visibility of these within the research on the topic. Researchers with an $\mathrm{H}$ index greater than 50 are observed, which reflects the visibility translated into the number of highly cited works.

Table 1. Top 20 most productive authors

\begin{tabular}{|c|l|c|l|l|c|}
\hline No. & \multicolumn{1}{|c|}{ Authors } & ND & \multicolumn{1}{|c|}{ Institution } & \multicolumn{1}{|c|}{ Country } & H index \\
\hline 1 & Jeong, J.S. & 6 & Universidad de Extremadura & Spain & 13 \\
\hline 2 & González-Gómez, D. & 5 & Universidad de Extremadura & Spain & 27 \\
\hline 3 & Hwang, G.J. & 5 & $\begin{array}{l}\text { National Taiwan University of Science and } \\
\text { Technology }\end{array}$ & Taiwan & 57 \\
\hline 4 & Mclaughlin, J.E. & 5 & The University of North Carolina at Chapel Hill & United States & 15 \\
\hline 5 & Cañada-Cañada, F. & 4 & Universidad de Extremadura & Spain & 21 \\
\hline 6 & Chen, N.S. & 4 & National Yunlin University of Science and & Taiwan & 38 \\
\hline
\end{tabular}


Paper-Flipped Classroom in Higher Education: A Bibliometric Analysis and Proposal of a Framework...

\begin{tabular}{|c|l|c|l|l|c|}
\hline & & & Technology & & \\
\hline 7 & Hinojo-Lucena, F. J. & 4 & Universidad de Granada & Spain & 7 \\
\hline 8 & Long, Taotao & 4 & Huazhong Normal University & China & 3 \\
\hline 9 & Sointu, E. & 4 & Itä-Suomen yliopisto & Finland & 8 \\
\hline 10 & Waugh, M. & 4 & The University of Tennessee, Knoxville & United States & 4 \\
\hline 11 & Zainuddin, Z. & 4 & The University of Hong Kong & Hong Kong & 7 \\
\hline 12 & Broedel-zaugg, K. & 3 & Marshall University & United States & 7 \\
\hline 13 & Cummins, J. & 3 & The University of Tennessee, Knoxville & United States & 2 \\
\hline 14 & De Wever, B. & 3 & Universiteit Gent & Belgium & 26 \\
\hline 15 & Fatima, S.S. & 3 & The Aga Khan University & Pakistan & 11 \\
\hline 16 & Gillette, C. & 3 & Wake Forest School of Medicine & United States & 12 \\
\hline 17 & Hafidi, M. & 3 & Université Badji Mokhtar - Annaba & Algeria & 3 \\
\hline 18 & Hew, K.F. & 3 & The University of Hong Kong & Hong Kong & 30 \\
\hline 19 & Hirsto, L. & 3 & Itä-Suomen yliopisto & Finland & 6 \\
\hline 20 & Kinshuk & 3 & University of North Texas & United States & 19 \\
\hline
\end{tabular}

ND: number of documents in the dataset

\subsection{Indicators of collaboration (2012 - October 2020)}

The increase in collaborative work, generated by various scientific and social phenomena, has impacted on the development and quality of scientific systems and disciplines. With regard to the collaboration of authors, $75 \%$ of the papers were written in collaboration (two or more authors per published document) and $47 \%$ of these papers were published in collaboration with three or more authors, with the highest records in the period 2014-2018 (Table 2). This highly collaborative behaviour, which has tended to increase in recent years, is now common practice in most scientific disciplines. This panorama is generated by technological development, the interdisciplinarity present in the thematic areas, even in the Social Sciences and Humanities where practices have been marked by writing with little collaboration and with this change there is no doubt that the visibility and impact of the research produced will increase.

Table 2. Distribution of publications according to year and number of authors

\begin{tabular}{|c|c|c|c|c|c|c|c|c|c|c|}
\hline \multirow{2}{*}{$\begin{array}{c}\text { No. of } \\
\text { authors }\end{array}$} & \multicolumn{9}{|c|}{ Year of Publication } & \multirow{2}{*}{ Total } \\
\hline & 2012 & 2013 & 2014 & 2015 & 2016 & 2017 & 2018 & 2019 & Oct 2020 & \\
\hline 1 & 1 & 3 & 4 & 23 & 24 & 28 & 40 & 44 & 27 & $194(25 \%)$ \\
\hline 2 & 0 & 2 & 4 & 18 & 28 & 33 & 45 & 46 & 43 & $219(28 \%)$ \\
\hline$>=3$ & 0 & 1 & 11 & 23 & 26 & 61 & 59 & 106 & 82 & $369(47 \%)$ \\
\hline Total & 1 & 6 & 19 & 64 & 78 & 122 & 144 & 196 & 152 & 782 \\
\hline
\end{tabular}

Figure 3 presents the three indicators of collaboration; index, degree and collaboration coefficient. At the top are the values of the collaboration index (CI) showing the 
average number of authors per document. Thus, in 2014 and 2020, the highest values of the study period appear, with the average value of the whole set being 2.8 authors per document. The lower part of Fig. 3 shows the values of the degree of collaboration (CG), which range from 0 to 1 . From 2015 onwards, there is a tendency for the CG to grow, which in 2020 reached the value of 0.82 . This indicates that $82 \%$ of documents were written in collaboration ( 2 or more authors).

Finally, the collaboration coefficient (CC) proposed by Ajiferuke, Burrel \& Tague [40] adds up the benefits of the CI and the CG which takes into account the difference between different multiple authorships. It also reaches its maximum value in the year 2020 with 0.54 . The values of the CG reflect the complement of the inverse average weighted by the number of authors.

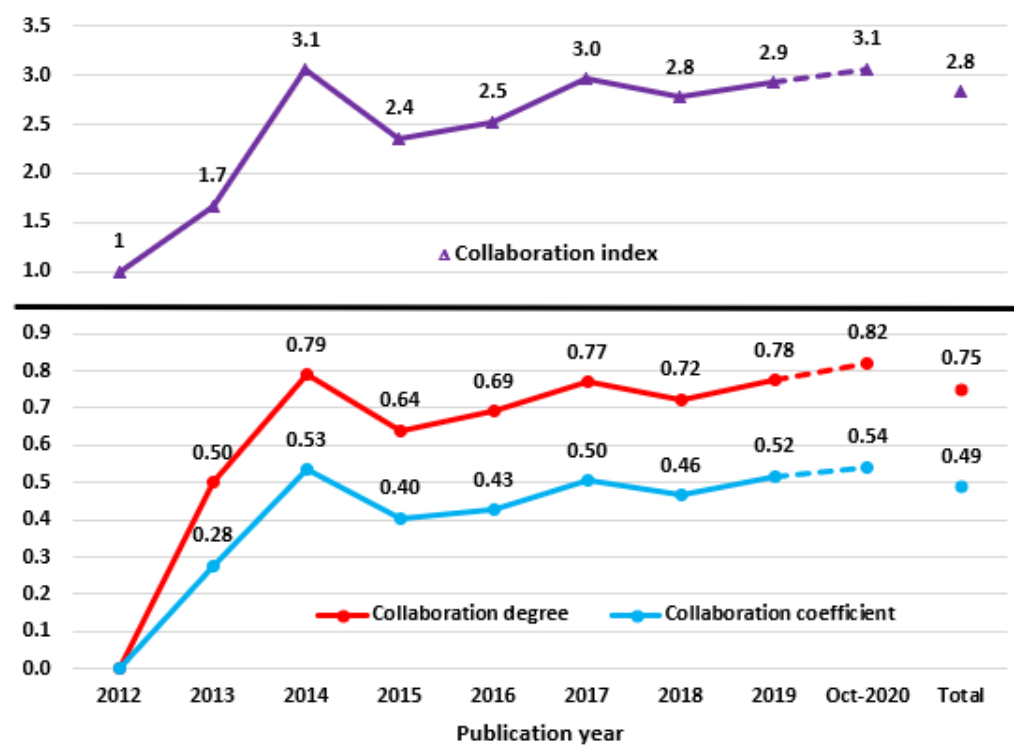

Fig. 3. Index, degree and coefficient of author collaboration

\subsection{Keywords co-occurrence network}

The co-occurrence analysis was performed with the 80 descriptors of more than 5 occurrences. Each node represents a keyword and its size is proportional to the total link strength of co-occurrence of keywords (Fig. 4). The overlay shows the use of the terms according to the average year of publication where the keyword appears, observing the evolution of the most important topics within the FC in higher education. The most frequent items published on average in 2017 are shown in blue, and those that appear in documents published on average in 2019 are shown in red. It is to be expected that flipped classroom is the most frequent keyword: however, items related to active learning, online learning, blended learning, among others, stand out. 


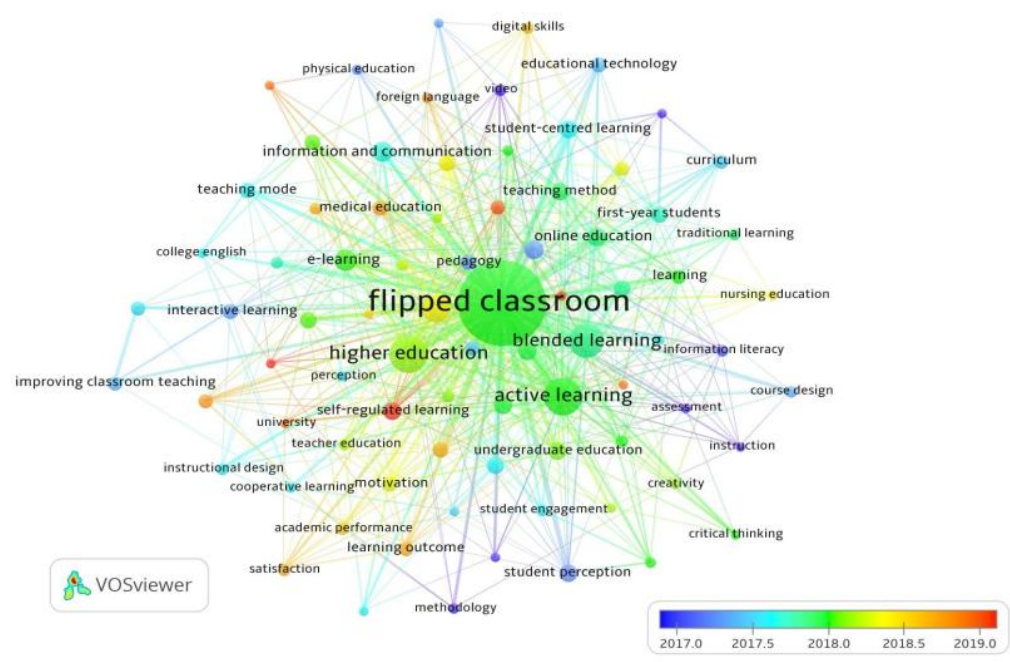

Fig. 4. Overlay visualization of keywords

For the analysis of the terms according to the frequency of appearance on the network, those with more than 10 appearances were taken into account, and 41 terms met this threshold. A significant difference is observed between flipped classroom with 569 appearances and the rest of terms with frequencies lower than 100 and a homogeneous amount between them, a trend that is related to being the base term of the analysis and the one used in the search equation (Table 3). The proximity of the FC to active learning, blended learning, e-learning, ICT, teaching method, among others, is evident. This could reveal that the implementation of the FC is accompanied by these important current trends. Figure 4 and Table 3 can be used as a reference for organising search and retrieval equations, or for identifying FC issues in future research.

Table 3. Most frequent keywords $(n \geq 10)$

\begin{tabular}{|c|l|c|c|l|c|}
\hline No. & \multicolumn{1}{|c|}{ Term } & NO & No. & \multicolumn{1}{c|}{ Term } & NO \\
\hline 1 & flipped classroom & 569 & 22 & mooc & 16 \\
\hline 2 & active learning & 90 & 23 & interactive learning & 15 \\
\hline 3 & higher education & 90 & 24 & medical education & 15 \\
\hline 4 & blended learning & 72 & 25 & pedagogy & 15 \\
\hline 5 & flipped learning & 53 & 26 & educational technology & 14 \\
\hline 6 & e-learning & 29 & 27 & gamification & 14 \\
\hline 7 & information and communication & 25 & 28 & motivation & 14 \\
\hline 8 & technology & 22 & 29 & teaching mode & 14 \\
\hline 9 & teaching & 20 & 30 & learning & 13 \\
\hline 10 & teaching method & 20 & 31 & curriculum & 12 \\
\hline 11 & student perception & 19 & 32 & improving classroom teaching & 12 \\
\hline 12 & technologies & 19 & 33 & learning outcome & 12 \\
\hline 13 & collaborative learning & 18 & 34 & engineering education & 11 \\
\hline 14 & education & 18 & 35 & learning performance & 11 \\
\hline
\end{tabular}


Paper-Flipped Classroom in Higher Education: A Bibliometric Analysis and Proposal of a Framework...

\begin{tabular}{|l|l|l|l|l|c|}
\hline 15 & self-regulated learning & 18 & 36 & peer learning & 11 \\
\hline 16 & student-centred learning & 18 & 37 & problem based learning & 11 \\
\hline 17 & undergraduate education & 18 & 38 & teaching/learning strategies & 11 \\
\hline 18 & english as a foreign language & 17 & 39 & academic performance & 10 \\
\hline 19 & english language teaching & 17 & 40 & information literacy & 10 \\
\hline 20 & engagement & 16 & 41 & instructional design & 10 \\
\hline 21 & first-year students & 16 & & & \\
\hline
\end{tabular}

NO: Number of occurrences

Similarly, an analysis of the clusters and their main descriptors was carried out which allowed the identification of thematic approaches revolving around FC in higher education (Table 4). Each cluster is made up of the keywords with the greatest strength among them according to the cooccurrence force of keywords obtained with the VOSviewer programme. Thus, the FC has to do with its use in the teaching of English as a foreign language (cluster 1), through active learning, autonomous learning, collaborative learning (clusters 2, 3 and 4), the use of ICT (cluster) and the improvement of academic performance (cluster 10).

Table 4. Distribution of clusters and their respective keywords

\begin{tabular}{|c|c|c|c|}
\hline Cluster & Focus & Top of terms and their frequency of appearance & Size \\
\hline Cluster 1 & $\begin{array}{l}\text { Flipped classroom, com- } \\
\text { mitment and its use in } \\
\text { teaching English }\end{array}$ & $\begin{array}{l}\text { achievement levels (6), engagement (16), english as a } \\
\text { foreing language (17), english language teaching (17), } \\
\text { flipped classroom (569), flipped learning (53) }\end{array}$ & $\begin{array}{l}15 \\
\text { terms }\end{array}$ \\
\hline Cluster 2 & $\begin{array}{l}\text { Active learning and } \\
\text { creative thinking }\end{array}$ & $\begin{array}{l}\text { active learning (90), assessment (6), course design (8), } \\
\text { creativity (6), creative thinking (6), information literacy } \\
(10)\end{array}$ & $\begin{array}{l}11 \\
\text { terms }\end{array}$ \\
\hline Cluster 3 & $\begin{array}{l}\text { Autonomous, cooperative } \\
\text { and experiential learning }\end{array}$ & $\begin{array}{l}\text { autonomous learning (8), college english (6), cooperative } \\
\text { learning (7), experiential learning (6), mooc (16) }\end{array}$ & 8 terms \\
\hline Cluster 4 & $\begin{array}{l}\text { Collaborative and online } \\
\text { learning }\end{array}$ & $\begin{array}{l}\text { collaborative learning (18), curriculum (12), e-learning (29), } \\
\text { first-year students (16), internet/web-based learning (6) }\end{array}$ & 8 terms \\
\hline Cluster 5 & $\begin{array}{l}\text { Technology and digital } \\
\text { skills }\end{array}$ & $\begin{array}{l}\text { digital skills (9), educational technology (14), engineering } \\
\text { education (11), medical education (15), nursing education } \\
\text { (6), online education (22) }\end{array}$ & 8 terms \\
\hline Cluster 6 & $\begin{array}{l}\text { Higher education, tech- } \\
\text { nology and teaching } \\
\text { methods }\end{array}$ & $\begin{array}{l}\text { education (18), foreign language (7), higher education (90), } \\
\text { information and communication technology (25), learning } \\
(13), \text { teaching methods }(20)\end{array}$ & 6 terms \\
\hline Cluster 7 & $\begin{array}{l}\text { Academic performance } \\
\text { and student perspective }\end{array}$ & $\begin{array}{l}\text { academic performance (10), methodology (7), peer learning } \\
(11), \text { student perception (19), student engagement (8) }\end{array}$ & 6 terms \\
\hline Cluster 8 & $\begin{array}{l}\text { Assessment and teaching } \\
\text { and learning strategies }\end{array}$ & $\begin{array}{l}\text { evaluation (8), improvement classroom teaching (12), } \\
\text { instructional design (10), interactive learning (15), teach- } \\
\text { ing/learning strategies (11) }\end{array}$ & 6 terms \\
\hline Cluster 9 & $\begin{array}{l}\text { Methodologies and stu- } \\
\text { dent attitudes }\end{array}$ & $\begin{array}{l}\text { attitudes (8), blended learning (72), case study (6), gamifi- } \\
\text { cation (14), traditional learning (8) }\end{array}$ & 5 terms \\
\hline $\begin{array}{l}\text { Cluster } \\
10\end{array}$ & Learning performance & $\begin{array}{l}\text { content learning (6), data science (6), learning performance } \\
(11), \text { physical education (7), team-based learning (9) }\end{array}$ & 5 terms \\
\hline
\end{tabular}




\subsection{Framework proposal}

Based on some results of the bibliometric analysis and the background review, documents were chosen as the theoretical source for the proposal of a framework. The following criteria were applied: (a) papers by more productive authors, (b) results from the keywords co-occurrence network, (c) papers with more citations in the Web of Science and Scopus databases, (d) seminal studies by Bergman and Sams, and, (e) FC studies in the context of covid-19. This made it possible to propose a framework, a useful tool for higher education professors to implement FC in their classes either in the form of face-to-face, blended or online learning education (Fig. 5). From the literature reviewed, it can be seen that there is no specific methodology that indicates the steps to follow to replicate a FC, nor is there a list of tasks that can be followed to ensure good results [13]. The proposal has five components (Fig. 5) and is based on the studies of Bergmann \& Sams [4], Bergmann \& Sams [13], Jeong et al. [41], Kim et al. [20], Lo \& Hwang [21], O'Flaherty \& Phillips [33], Ożadowicz [16] and Hew et al. [18].

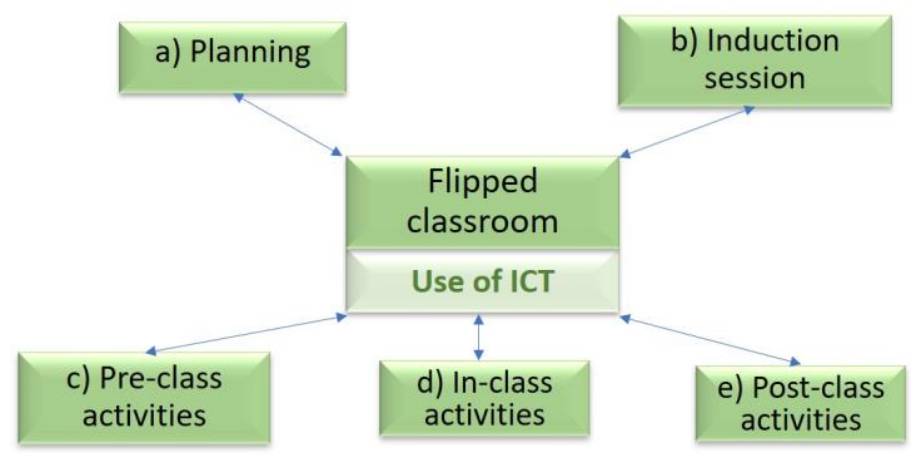

Fig. 5. Descriptive framework to implement a FC in higher education. ICT: Information and communication technology.

Source: Own elaboration

Planning: This is the process prior to the development of the teaching/learning process under the FC approach. Among the considerations that the professor must take into account are; (a) to design the subject for the academic cycle knowing the type of pedagogy and didactics to be used, (b) to be trained in the use of ICT, which includes the university platform, computer programs to prepare teaching materials and to record the sessions, (c) to design the learning sessions considering the type of educational modality (classroom, blended or non-classroom) and, (d) to design the assessment system and the learning evidence with qualification headings or other assessment instruments.

Induction session on the first day of class: It is important that the student is clear about how to work under the FC approach, because the lack of clarity in the new role the student has can play against their learning process. Among the main activities of the professor are (a) presenting the syllabus and explaining the role of the students 
and the professor under this methodology, (b) giving an induction on the use of technologies to be used, as well as teaching how to watch the videos and how to read the readings, (c) choosing forms of communication and organisation before, during and after the sessions. If it is online education, the professor must indicate and explain the type of web videoconference to be used. Several options are offered: Zoom, Google Meet, Cisco Webex, Microsoft Teams, among others, and (d) explain the evaluation criteria, and may accept suggestions from students.

Pre-class activities: For the professor, (a) seek and select up-to-date information on the subject of the class, (b) prepare and publish the materials (videos, readings, presentations, computer graphics, assessment rubrics), (c) communicate the availability of the pre-class material, and (d) prepare the self-assessment material for the students (through forms, video recording, Kahoot, Mentimeter or other means). Activities for the students, (a) review the class materials considering the guidelines given by the professor in the first session, (b) carry out the activities that allow them to check their self-learning, (c) generate questions about the revised material, and (d) take notes, record their questions and summarize what they are learning.

In-class activities: For the professor, (a) invite students to make a synthesis of what was seen in the previous session, (b) present the learning session in its global or joint form, (c) invite students to ask questions, (d) present the practical activities of the session (individual or group), here the importance of collaborative and team-based learning should be emphasized, and (e) give feedback on the topic and practical activities. For the students: (a) actively participate by asking questions, (b) participate in the hands-on activities, (c) after individual and/or group activities, they may respond to concepts in a collaborative way, (d) respond individually or collaboratively to session evaluations.

Post-class activities: Their use is not common in current FC practice, as additional work after class coupled with previous classes in the next class can produce a fatiguing effect on students. However, the professor can optionally: (a) offer the possibility of answering students' questions through forums from the platform, e-mails or other means of communication, and (ii) generate questions for students to reflect on the activities carried out.

\section{Discussion and Conclusion}

The purposes of this research were achieved which were to conduct a bibliometric analysis of FC in higher education and to propose a framework for implementing the FC. In this way, the article made several contributions to the scientific literature from the 782 refereed documents on the FC in higher education (2012-2020).

From the study period, the number of publications grew steadily in the sources analysed, this finding is in analogy with what [29], [31], [32] expounded. It starts 2012 with only one publication up to 152 documents in the year 2020 (October), this shows that FC research in higher education is in growing development. This increase is due, among other aspects, to the novel proposal of the methodology in the field of higher education, to the need to apply active methodologies of student-centred teaching and 
learning, and in this last stage, in response to online learning due to the covid-19 pandemic. As for the top 20 most productive authors in the flow of information about FC, it is observed that Jeong, J. S. from the University of Extremadura, Spain is the most productive with 6 documents in the period analysed. If we analyse the affiliations and countries of the authors, we can see the participation of several countries coming from almost all the continents of the planet, which is one more sample of the importance of this subject at a global level.

Collaboration indicators show a growing interest in collaborative practices among FC researchers in higher education. The highest levels of collaboration are evident between 2013 and 2014, with a CG of 0.50 to 0.80 , a CC of 0.28 to 0.53 and a CI of 1.7 to 3.1 authors per document. This phenomenon of collaboration not only reflects the need to generate local impact, but also responds to the motivation of complementing skills, obtaining recognition and visibility, increasing scientific productivity, among others [42]. With the development of science and the explosion of knowledge, nobody is an expert in everything, so scientific collaboration becomes a visible need in several disciplines [43], [44].

The analysis of the co-occurrence of keywords shows that the FC in higher education is of increasing interest for application in all professional areas with a specialised vision and close relation to active learning, e-learning, blended learning, information and communication technology, among other terms. This result is consistent with [31] who conducted a bibliometric study of the FC at all educational levels. Through this keywords analysis, the emphasis on FC research over the past few years has become apparent, as it responds to the current demands of education that go hand in hand with information and communication technologies (ICTs). The different clusters identified the main elements and approaches that are part of the FC and that complement its implementation in higher education.

The framework proposal in this paper was aimed at implementing the FC in higher education that could be taken into account to achieve better learning outcomes. The structure of the framework is based on five systematized components that include the design of the course, the induction of the first session with a clear presentation by the professor, who proposes mechanisms for clear connections between the class and outside the classroom. Then, the activities before, during and after the class were detailed by the students and the professor as a guide. This framework is easily adaptable to the various modes of education (face-to-face, blended or online learning) that act in complicity with the use of ICT [12], [20], [21].

In the light of the results, it is recommended that future studies evaluate this issue from other bibliometric methodologies such as co-citation, bibliographic coupling, analysis of networks of institutions and countries. It is also recommended that new research include FC studies with the altmetrics indicators to determine their behaviour and impact on social media. In addition, the study of the FC and its relationship to other active learning pedagogical models can be included. Finally, it is proposed to develop a methodology similar to this article to study the implementation of other educational models, such as gamification, design thinking, connectivism, projectbased learning, among others. 


\section{Acknowledgement}

Thanks are extended to the research group CIGETMEN (Ciencias de la Información: Gestión, tecnologías, métricas, normas éticas y jurídicas) of the Facultad de Letras y Ciencias Humanas of the Universidad Nacional Mayor de San Marcos, and to the Dirección de Investigación of the Universidad Peruana de Ciencias Aplicadas.

\section{$6 \quad$ References}

[1] M. Prince, "Does active learning work? A review of the research," Journal of Engineering Education, vol. 93, no. 3. Wiley-Blackwell Publishing Ltd, pp. 223-231, Jul. 01, 2004. https://doi.org/10.1002/j.2168-9830.2004.tb00809.x

[2] S. Zayapragassarazan, Z.; Kumar, "Active Learning Methods," NTTC Bull., vol. 19, no. 1, pp. 3-5, 2012, Accessed: Nov. 22, 2020. [Online]. Available: https://eric.ed.gov/ ?id=ED538497

[3] J. F. Strayer, "How learning in an inverted classroom influences cooperation, innovation and task orientation," Learn. Environ. Res., vol. 15, no. 2, pp. 171-193, 2012. https://doi.org/10.1007/s10984-012-9108-4

[4] J. Bergmann and A. Sams, Flip Your Classroom: Reach Every Student in Every Class Every Day. International Society for Technology in Education, 2012.

[5] S. Deterding, D. Dixon, R. Khaled, and L. Nacke, "From Game Design Elements to Gamefulness: Defining "Gamification," in Proceedings of the 15th International Academic MindTrek Conference: Envisioning Future Media Environments, pp. 9-15, 2011. https://doi.org/10.1145/2181037.2181040

[6] S.-Y. Chan, Y. K. Lam, and T. F. Ng, "Student's perception on initial experience of flipped classroom in pharmacy education: Are we ready?," Innov. Educ. Teach. Int., vol. 57, no. 1, pp. 62-73, Jan. 2020. https://doi.org/10.1080/14703297.2018.1541189

[7] W. He, A. Holton, G. Farkas, and M. Warschauer, "The effects of flipped instruction on out-of-class study time, exam performance, and student perceptions," Learn. Instr., vol. 45, pp. 61-71, 2016. https://doi.org/10.1016/j.learninstruc.2016.07.001

[8] C. Aguilera-Ruiz, A. Manzano-León, I. Martínez-Moreno, M. C. Lozano-Segura, and C. Casiano Yanicelli, "El modelo Flipped Classroom," Rev. INFAD Psicol. Int. J. Dev. Educ. Psychol. Vol. 4, Núm. 1 n1.v4, Nov. 2017. https://doi.org/10.17060/ijodaep.2017.n1. v4.1055

[9] E. Aprianto, O. Purwati, and S. Anam, "Multimedia-Assisted Learning in a Flipped Classroom: A Case Study of Autonomous Learning on EFL University Students," Int. J. Emerg. Technol. Learn., vol. 15, no. 24, p. 114, 2020. https://doi.org/10.3991/ijet.v15i24.14017

[10] R. Brewer and S. Movahedazarhouligh, "Successful stories and conflicts: A literature review on the effectiveness of flipped learning in higher education," J. Comput. Assist. Learn., vol. 34, no. 4, pp. 409-416, Aug. 2018. https://doi.org/10.1111/jcal.12250

[11] K. Umam, T. Nusantara, I. N. Parta, E. Hidayanto, and H. Mulyono, "An application of flipped classroom in mathematics teacher education programme," Int. J. Interact. Mob. Technol., vol. 13, no. 3, pp. 68-80, 2019. https://doi.org/10.3991/ijim.v13i03.10207

[12] D. M. DePietro et al., "Medical Student Education During the COVID-19 Pandemic: Initial Experiences Implementing a Virtual Interventional Radiology Elective Course," Acad. Radiol., pp. 1-8, 2020. https://doi.org/10.1016/j.acra.2020.10.005 
[13] J. Bergmann and A. Sams, Dale vuelta a tu clase. Lleva tu clase a cada estudiante,en cualquier momento y cualquier lugar. Madrid: Fundación Santa María-Ediciones SM, 2014.

[14] L. Abeysekera and P. Dawson, "Motivation and cognitive load in the flipped classroom: definition, rationale and a call for research," High. Educ. Res. Dev., vol. 34, no. 1, pp. 114, Jan. 2015. https://doi.org/10.1080/07294360.2014.934336

[15] F. J. Hinojo-Lucena, Á. C. Mingorance-Estrada, J. M. Trujillo-Torres, I. Aznar-Díaz, and M. P. Cáceres-Reche, "Incidence of the flipped classroom in the physical education students' academic performance in university contexts," Sustain., vol. 10, no. 5, 2018. https://doi.org/10.3390/su10051334

[16] A. Ożadowicz, "Modified blended learning in engineering higher education during the COVID-19 lockdown-building automation courses case study," Educ. Sci., vol. 10, no. 10, pp. 1-20, 2020. https://doi.org/10.3390/educsci10100292

[17] UNESCO, "Education: From disruption to recovery," 2020. https://en.unesco.org/covid 19/educationresponse (accessed Dec. 16, 2020).

[18] K. F. Hew, C. Jia, D. E. Gonda, and S. Bai, "Transitioning to the 'new normal' of learning in unpredictable times: pedagogical practices and learning performance in fully online flipped classrooms," Int. J. Educ. Technol. High. Educ., vol. 17, no. 1, 2020. https://doi.org/10.1186/s41239-020-00234-x

[19] T. Tang, A. M. Abuhmaid, M. Olaimat, D. M. Oudat, M. Aldhaeebi, and E. Bamanger, "Efficiency of flipped classroom with online-based teaching under COVID-19," Interact. Learn. Environ., pp. 1-12, Sep. 2020. https://doi.org/10.1080/10494820.2020.1817761

[20] M. K. Kim, S. M. Kim, O. Khera, and J. Getman, "The experience of three flipped classrooms in an urban university: An exploration of design principles," Internet High. Educ., vol. 22, pp. 37-50, 2014. https://doi.org/10.1016/j.iheduc.2014.04.003

[21] C. K. Lo and G. J. Hwang, "How to advance our understanding of flipped learning: Directions and a descriptive framework for future research," Knowl. Manag. E-Learning, vol. 10, no. 4, pp. 441-454, 2018. https://doi.org/10.34105/j.kmel.2018.10.027

[22] O. V. Gross and A. Pritchard, "Documentation notes," J. Doc., vol. 25, no. 4, pp. 344-349, Jan. 1969. https://doi.org/10.1108/eb026482

[23] B. Vargas-Quesada and F. de Moya Aragón, Visualizing the structure of science. New York, NY, 2007. https://doi.org/10.1007/3-540-69728-4

[24] R. Arencibia-Jorge and F. De-Moya-Anegón, "La evaluación de la investigación científica: Una aproximación teórica desde la cienciometría," Acimed, vol. 17, no. 4, pp. 1-27, 2008.

[25] W. Glänzel, "Bibliometric methods for detecting and analysing emerging research topics," Prof. la Inf., vol. 21, no. 2, pp. 194-201, 2012. https://doi.org/10.3145/epi.2012.mar.11

[26] J. A. Moral-Munoz, A. G. López-Herrera, E. Herrera-Viedma, and M. J. Cobo, "Science Mapping Analysis Software Tools: A Review BT - Springer Handbook of Science and Technology Indicators," W. Glänzel, H. F. Moed, U. Schmoch, and M. Thelwall, Eds. Cham: Springer International Publishing, 2019, pp. 159-185. https://doi.org/10.1007/9783-030-02511-3 7

[27] O. Ellegaard and J. A. Wallin, "The bibliometric analysis of scholarly production: How great is the impact?," Scientometrics, vol. 105, no. 3, pp. 1809-1831, Dec. 2015. https://doi.org/10.1007/s11192-015-1645-Z

[28] N. J. van Eck and L. Waltman, "Visualizing Bibliometric Networks," in Measuring Scholarly Impact, Springer International Publishing, 2014, pp. 285-320. https://doi.org/ 10.1007/978-3-319-10377-8_13 
[29] L. Yang, T. Sun, and Y. Liu, "A Bibliometric Investigation of Flipped Classroom Research during 2000-2015,” Int. J. Emerg. Technol. Learn., vol. 12, no. 06, pp. 178-186, Jun. 2017. https://doi.org/10.3991/ijet.v12i06.7095

[30] T. S. Al-Shabibi and M. A. K. Al-Ayasra, "Effectiveness of the flipped classroom strategy in learning outcomes (bibliometric study)," Int. J. Learn. Teach. Educ. Res., vol. 18, no. 3, pp. 96-127, 2019. https://doi.org/10.26803/ijlter.18.3.6

[31] J. Julia et al., "Flipped classroom educational model (2010-2019): A bibliometric study," Eur. J. Educ. Res., vol. 9, no. 4, pp. 1377-1392, 2020. https://doi.org/10.12973/eujer.9.4.1377

[32] H. L. Tsai and J. F. Wu, "Bibliometric analysis of flipped classroom publications from the Web of Science Core Collection published from 2000 to 2019," Sci. Ed., vol. 7, no. 2, pp. 163-168, 2020. https://doi.org/10.6087/KCSE.212

[33] J. O'Flaherty and C. Phillips, "The use of flipped classrooms in higher education: A scoping review," Internet High. Educ., vol. 25, pp. 85-95, 2015. https://doi.org/10.1016/ j.iheduc. 2015.02.002

[34] M. Lundin, A. Bergviken Rensfeldt, T. Hillman, A. Lantz-Andersson, and L. Peterson, "Higher education dominance and siloed knowledge: a systematic review of flipped classroom research,” Int. J. Educ. Technol. High. Educ., vol. 15, no. 1, 2018. https://doi.org/ 10.1186/s41239-018-0101-6

[35] T. Sola-Martínez, I. Aznar-Díaz, J. M. Romero-Rodríguez, and A.-M. Rodríguez-García, "Eficacia del Método Flipped Classroom en la Universidad: Meta-Análisis de la Producción Científica de Impacto," REICE. Rev. Iberoam. sobre Calidad, Efic. y Cambio en Educ., vol. 17, no. 1, p. 25, 2019. https://doi.org/10.15366/reice2019.17.1.002

[36] R. Carver, "Theory for practice: A framework for thinking about experiential education," J. Exp. Educ., vol. 19, no. 1, pp. 8-13, May 1996. https://doi.org/10.1177/1053825996 $\underline{01900102}$

[37] N. J. Van Eck and L. Waltman, "How to normalize cooccurrence data? An analysis of some well-known similarity measures," J. Am. Soc. Inf. Sci. Technol., vol. 60, no. 8, pp. 1635-1651, Aug. 2009. https://doi.org/10.1002/asi.21075

[38] N. J. van Eck and L. Waltman, "Software survey: VOSviewer, a computer program for bibliometric mapping," Scientometrics, vol. 84, no. 2, pp. 523-538, Aug. 2010. https://doi.org/10.1007/s11192-009-0146-3

[39] L. Waltman, N. J. van Eck, and E. C. M. Noyons, "A unified approach to mapping and clustering of bibliometric networks," J. Informetr., vol. 4, no. 4, pp. 629-635, 2010. https://doi.org/10.1016/i.joi.2010.07.002

[40] I. Ajiferuke, Q. Burell, and J. Tague, "Collaborative coefficient: A single measure of the degree of collaboration in research," Scientometrics, vol. 14, no. 5, pp. 421-433, 1988. https://doi.org/10.1007/BF02017100

[41] J. S. Jeong, D. González-Gómez, and F. Cañada-Cañada, "How does a flipped classroom course affect the affective domain toward science course?," Interact. Learn. Environ., vol. 0, no. 0, pp. 1-13, 2019. https://doi.org/10.1080/10494820.2019.1636079

[42] D. Lazcano-Peña and D. Reyes-Lillo, "Redes académicas en la investigación en Comunicación en Chile: análisis de co-autorías en el trabajo científico," Rev. española Doc. Científica, vol. 43, no. 1, p. 259, 2020. https://doi.org/10.3989/redc.2020.1.1626

[43] W. Glanzel, "Coauthorship Patterns and Trends in the Sciences (1980-1998): A Bibliometric Study with Implications for Database Indexing and Search Strategies," 2002. Accessed: Nov. 29, 2020. [Online]. Available: https://www.ideals.illinois.edu/bitstream/ handle/2142/8409/librarytrendsv50i3k_opt.pdf?seq 
[44] M. Franceschet, "Collaboration in computer science: A network science approach," J. Am. Soc. Inf. Sci. Technol., vol. 62, no. 10, pp. 1992-2012, Oct. 2011. https://doi.org/ $\underline{10.1002 / a s i .21614}$

\section{$7 \quad$ Authors}

Cesar H. Limaymanta has a degree in Pedagogy and Humanities, a Master's degree in Mathematical Statistics and teaches Bibliometrics and Statistics. He is a consultant in the empowerment, visibility and standardization of scientific production. His lines of research are Bibliometrics, Scientometrics and INFOLIT.

https://orcid.org/0000-0002-8797-4275

Ludgarda Apaza-Tapia teaches at the School of Accounting and Financial Sciences of the Universidad Nacional de San Agustín de Arequipa, Perú. Her research areas are Philosophy-Arts, Systems Engineering and Flipped Classroom. https://orcid.org/0000-0001-8894-3879

Elizabeth Vidal is a professor in the Computer and Systems Engineering Department of the Universidad Nacional de San Agustín de Arequipa, Perú. She researches topics of improvement of the teaching/learning process with the use of ICT and the game-oriented approach to teaching. https://orcid.org/0000-0002-8367-9439

Orlando Gregorio-Chaviano is a librarian and professor of Bibliometrics at the Pontificia Universidad Javeriana. Bogotá, Colombia. His lines of research are Bibliometrics and Science Evaluation. https://orcid.org/0000-0002-3064-8639

Article submitted 2021-01-17. Resubmitted 2021-02-26. Final acceptance 2021-02-27. Final version published as submitted by the authors. 